\title{
Is Low-Dose Streptozotocin in Rats an Adequate Model for Gestational Diabetes Mellitus?
}

\author{
Silvia Caluwaerts, $\mathrm{PhD}$, Kathleen Holemans, $\mathrm{PhD}$, Rita van Bree, \\ Johan Verhaeghe, MD, PhD, and F. André Van Assche, MD, PhD
}

\begin{abstract}
OBJECTIVE: To examine the use of streptozotocin (SZ) in rats as a model for gestational diabetes mellitus (GDM).

Methods: We studied various doses of $S Z$, either as a single administration (30, 35, 40, or 50 $\mathrm{mg} / \mathrm{kg}$, intraperitoneally) on day 1 of pregnancy or as 2 low doses (30 and 20 or 30 and $30 \mathrm{mg} / \mathrm{kg}$ ) administered 2 days before mating and on day 1 of pregnancy. We examined the effect on maternal and fetal glucose and insulin concentrations and on fetal weight on day 20 of pregnancy. In a second series of experiments, we studied two groups (SZ 30/20 and SZ 35) with fetal hyperinsulinemia on day 20 of pregnancy. We performed an intravenous glucose tolerance test (IVGTT) on day 20, and in separate groups we reassessed fetal weight and insulin concentrations at term (day 22).

Results: There was considerable variability in glucose concentrations with most $S Z$ doses. Lower doses of $S Z(30,30 / 20$, and $35 \mathrm{mg} / \mathrm{kg})$ did not significantly increase maternal and fetal glucose levels, in contrast to higher doses of $S Z(30 / 30$ and $50 \mathrm{mg} / \mathrm{kg})$. Fetuses were smaller on day 20 with all doses except $S Z$ 30 and SZ 30/20; fetal insulin concentrations were elevated with $S Z 30,30 / 20$, and 35. The IVGTT showed glucose intolerance in $S Z 35$ and $S Z 30 / 20$, but the insulin response was unaffected in either group. Fetuses were smaller on day 22 in both these $S Z$ groups, whereas fetal insulin levels at term were not different compared with controls.

CONCLUSION: Low-dose SZ is not a good model for GDM because of the high variability in glucose levels, the normal insulin response to a glucose load, the absence of fetal macrosomia, and the inconsistent effect on fetal insulin concentrations. (J Soc Gynecol Investig 2003;10:216-21) Copyright (C) 2003 by the Society for Gynecologic Investigation.
\end{abstract}

KeY wORDS: Gestational diabetes mellitus, pregnancy, rats, streptozotocin.

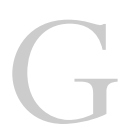
estational diabetes mellitus (GDM) is a frequent complication of pregnancy, affecting $3.5 \%$ of pregnancies in the United States in $1988 .{ }^{1}$ Because obesity and age are major risk factors for $\mathrm{GDM},{ }^{2}$ the prevalence of GDM is increasing. ${ }^{3}$ Although GDM may represent a previously unrecognized state of continuous hyperglycemia (ie, diabetes), most women with GDM show glucose intolerance that does not persist after pregnancy. Women with GDM have been shown to be more insulin-resistant than normal pregnant women, and their insulin secretion is defective relative to the degree of insulin resistance. ${ }^{4}$ Babies of women with poorly controlled GDM are well known to be macrosomic, hyperglycemic, and hyperinsulinemic at birth. ${ }^{5}$

Research into GDM has been hampered by the lack of

From the Department of Obstetrics and Gynecology, Katholieke Universiteit Leuven, Leuven, Belgium.

Drs. Caluwaerts and Holemans contributed equally to this article.

S. Caluwaerts and this project were supported by a grant from the Katholieke Universiteit Leuven (Verkennende Internationale Samenwerking, ZKA 5850).

Address correspondence and reprint requests to: Silvia Caluwaerts, $\mathrm{PhD}$, Department of Obstetrics and Gynecology, U.Z. Gasthuisberg, Herestraat 49, 3000 Leuven, Belgium. E-mail: silvia.caluwaerts@med.kuleuven.ac.be

Copyright (C) 2003 by the Society for Gynecologic Investigation. Published by Elsevier Inc. universally accepted animal models. ${ }^{6}$ The most frequently used method is to inject a diabetogenic drug, such as alloxan or, more commonly, streptozotocin (SZ) into rats or rabbits. Because of the glucose compound in its chemical structure, $\mathrm{SZ}$ is taken up by the pancreatic $\beta$ cells through low-affinity binding to the glucose transporter GLUT-2. ${ }^{7}$ Streptozotocin causes damage to the plasma membrane and the DNA of the $\beta$ cells, resulting in necrosis. ${ }^{8,9}$ Although SZ clearly is toxic for $\beta$ cells, its half-life is only 30 minutes. ${ }^{10}$ Interestingly, human $\beta$ cells are resistant to $\mathrm{SZ}^{11}$ A robust dose of $\mathrm{SZ}$ in rats induces permanent hyperglycemia and hypoinsulinemia within 48 hours, ${ }^{12,13}$ which has been used by numerous research groups, including ours, as a model for type 1 diabetes during pregnancy. ${ }^{14,15}$ We have also studied pregnancies in spontaneously diabetic biobreeding rats, which develop an autoimmune form of type 1 diabetes. ${ }^{16}$ Severe maternal hyperglycemia invariably is accompanied by growth retardation of the fetuses, probably because of a reduction in uteroplacental blood flow. ${ }^{17}$ Fetal insulin levels were found to be normal ${ }^{18}$ or decreased. ${ }^{14-16}$

The use of lower doses of SZ during pregnancy has produced inconsistent results. In some studies, fetal growth retar- 
dation was observed irrespective of the SZ dose. ${ }^{19-21}$ In other studies, a proportion of the fetuses in the low-dose SZ groups were found to be larger than control fetuses, ${ }^{22-25}$ which was considered to be the experimental equivalent of human fetal macrosomia. In those studies, fetal insulin levels were variably reported to be normal ${ }^{20}$ or elevated. ${ }^{22-25}$

Given these inconsistencies, we set up a comprehensive study using six different doses and administration modes of SZ, which was given intraperitoneally (i.p.). The experimental questions we sought to answer were (1) which dose of SZ consistently produces mild hyperglycemia or glucose intolerance during pregnancy? (2) Is fetal macrosomia and hyperinsulinemia observed with any dose of SZ?

\section{MATERIALS AND METHODS}

All experiments were reviewed and approved by the Local Ethics Committee for animal procedures (Katholieke Universiteit, Leuven, Belgium).

Wistar rats (Charles River Laboratories, Wilmington, MA) aged 100-120 days were used in all experiments. The rats were kept in controlled conditions of light (12 hour light-dark cycle) and humidity, were fed standard laboratory chow ad libitum (Trouw, Gent, Belgium), and had free access to tap water. Before the start of the experiments, the rats were allowed to adapt for 1 week. The animals were then weighed, and a blood sample was taken from the tip of the tail for the determination of glucose and insulin levels. Vaginal wet smears were made to determine the estrous cycle of the rats. On the evening before estrus, female rats were housed overnight with male rats; the presence of spermatozoa in a vaginal smear the next morning was defined as day 1 of pregnancy. Streptozotocin (Pharmacia, North Peapack, NJ) was dissolved immediately before use in a phosphate buffer acidified to $\mathrm{pH} 4.2$ with citric acid and was administered i.p.

\section{Dose-Response Study of SZ (Study 1)}

Rats (six rats per group) were injected with a single dose of SZ (either $30,35,40$, or $50 \mathrm{mg} / \mathrm{kg}$ ) on day 1 of pregnancy. Two additional groups of rats $(n=6)$ were injected with two low doses of SZ, the first injection 2 days before mating $(30 \mathrm{mg} / \mathrm{kg}$ SZ) and the second on day 1 of pregnancy (30 or $20 \mathrm{mg} / \mathrm{kg}$ SZ). These groups are referred to as SZ 30/30 and SZ 30/20, respectively. Data from SZ-injected rats were compared with data from non-SZ-injected control rats $(n=6)$.

On days 6,13 , and 20 , the rats were weighed, and nonfasting blood samples were collected from the tip of the tail into heparinized tubes; the plasma was stored at $-20 \mathrm{C}$ for measurement of glucose and insulin concentrations. Glucose was determined using the glucose-oxidase method with a YSI 2300 Stat Plus Glucose Analyzer (Yellow Springs Instruments, Yellow Springs, $\mathrm{OH}$ ). Insulin was measured by radioimmunoassay with rat insulin as the standard (Linco Research, St. Charles, $\mathrm{MO}$ ) and a guinea pig anti-rat insulin antibody, donated by A. Kervran (Paris, France).

On day 20 of pregnancy, the rats were anesthetized with $0.24 \mathrm{mmol} / \mathrm{kg}$ pentobarbital i.p. (Sanofi, Brussels, Belgium), and fetuses were delivered by cesarean. Fetal blood was collected through axillary incisions and was pooled for all fetuses in each uterine horn (ie, two collections per litter). The plasma was stored for measurement of glucose and insulin concentrations. All fetuses and placentas were weighed, and the maternal rats were euthanized.

\section{Intravenous Glucose Tolerance Test and Fetal Data at Term in the SZ 35 and SZ 30/20 Groups (Study 2)}

On day 19 of pregnancy, rats (six per group) were anesthetized with ketamine $50 \mathrm{mg} / \mathrm{kg}$ i.p. (Parke-Davis, Zaventem, Belgium), xylazine $10 \mathrm{mg} / \mathrm{kg}$ i.p. (Bayer, Leverkusen, Germany), and atropine $0.25 \mathrm{mg} / \mathrm{kg}$ i.p. (Sterop, Brussels, Belgium). The jugular vein was cannulated, and the catheter (Degania Silicone, Degania Bet, Israel) was tunneled to the back. The animals recovered overnight, and water was available ad libitum. The following morning, a blood sample $(250 \mu \mathrm{L})$ was collected from the tip of the tail to determine basal glucose and insulin levels. A bolus of $1 \mathrm{~g} / \mathrm{kg}$ glucose $30 \%$ was injected intravenously. Blood glucose levels were determined by tailprick blood samples after 5, 10, 15, 30, 60, and 90 minutes using a glucometer (Glucocard Memory 2 GT-1640, Menarini, Florence, Italy). At 10, 30, and 90 minutes, a larger blood sample $(250 \mu \mathrm{L})$ was also collected from the tip of the tail, for simultaneous measurement of plasma insulin.

In a separate set of groups, we reassessed the fetal data on day 22 in the SZ 30/20, SZ 35, and control groups (six rats per group) as described for Study 1.

\section{Data Analysis}

Data are expressed as mean \pm standard error of the mean. Glucose and insulin levels during the intravenous glucose tolerance test (IVGTT) were analyzed by calculating the area under the curve (AUC) for each animal (GraphPad Software, San Diego, CA). Differences between groups were analyzed by one-way analysis of variance (ANOVA), using a software program (NCSS, Kaysville, UT). When ANOVA indicated a significant difference $(P<.05)$, Fisher's least significant difference (LSD) post hoc multiple comparison test was used to detect differences between groups. Fetal glucose and insulin levels on day 20 (study 1) and day 22 (study 2 ) were compared with unpaired $t$ tests.

\section{RESULTS}

\section{Dose-Response Study of SZ (Study 1)}

Weight gain during pregnancy was lower in the SZ 35 (73 \pm $2 \mathrm{~g})$ and SZ $50(72 \pm 14 \mathrm{~g})$ groups than in the control group $(112 \pm 3 \mathrm{~g})$ (ANOVA $P<.05)$, but there was no difference between any of the other SZ groups and the control group (data not shown).

Glucose concentrations decreased during pregnancy in control rats (ANOVA $P<.05$ ) and in SZ 30 rats (ANOVA $P<$ .001) (Figure 1, inset) but not in any of the other SZ groups. Figure 1 shows that mean glucose levels were elevated in the 


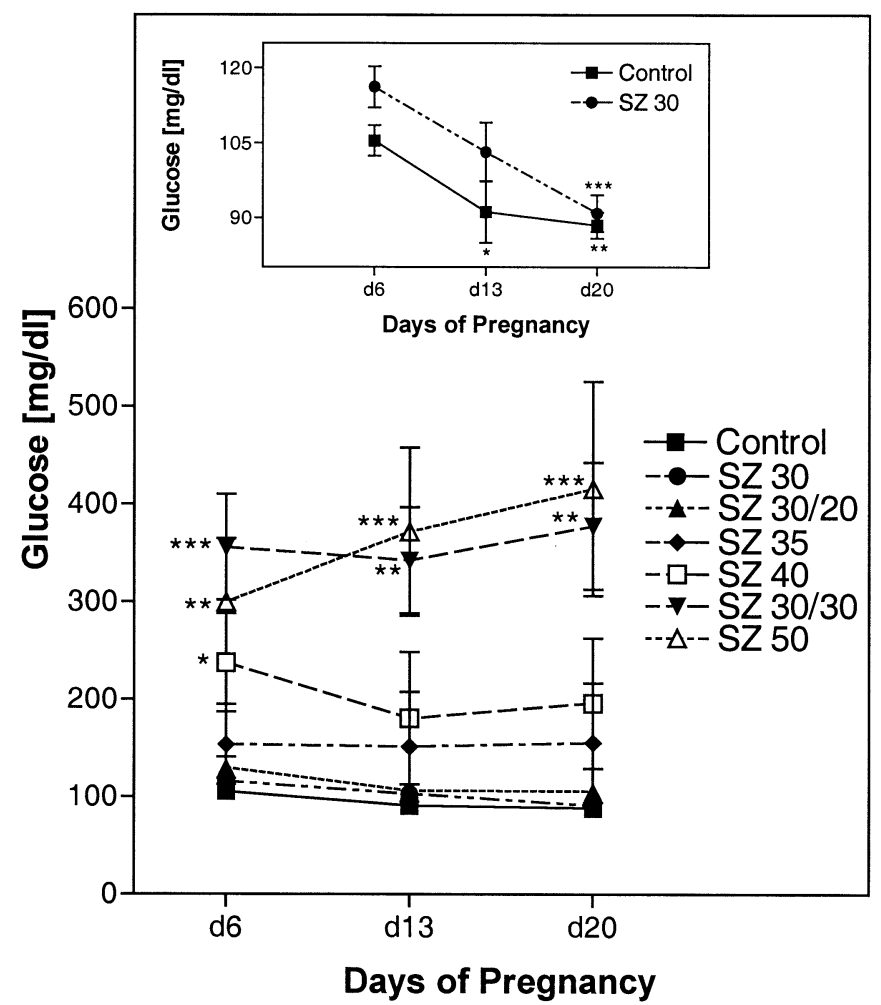

Figure 1. Plasma nonfasting glucose levels on days (d) 6, 13, and 20 of pregnancy in control and SZ-injected rats. Data are mean \pm standard error of the mean from six rats per group. One-way ANOVA indicated a highly significant difference among the groups $(P<.001$ on days 6,13 , and 20$)$, and the post hoc test (Fisher's LSD) revealed significant differences versus controls $\left({ }^{*} P<.05,{ }^{* *} P<.005\right.$, and $\left.{ }^{* * *} P<.001\right)$. The inset shows the groups in which a significant effect of pregnancy on glucose levels was detected (ANOVA $P<$ .001 for SZ 30 and $P<.05$ for control). Fisher's LSD test revealed significant differences versus day 6 .

SZ 30/30 and SZ 50 groups on days 6, 13, and 20, whereas the SZ 40 group was hyperglycemic only on day 6 . Figure 2 shows that $S Z$ produced considerable intragroup variability in glucose levels, particularly in SZ 35, SZ 40, SZ 30/30, and SZ 50. In SZ 30 and SZ 30/20 the results were more consistent, but mean glucose levels on day 20 were not significantly higher than in controls.

Insulin concentrations on day 20 were lower in the SZ $30 / 30(22 \pm 8 \mathrm{mU} / \mathrm{L}, P<.05)$ and SZ $50(26 \pm 8 \mathrm{mU} / \mathrm{L}, P$ $<.05)$ groups compared with controls $(55 \pm 9 \mathrm{mU} / \mathrm{L})$, but there was no difference between insulin levels of controls and any of the other SZ groups $(32 \pm 3,49 \pm 9,41 \pm 6$, and 46 $\pm 10 \mathrm{mU} / \mathrm{L}$, in the SZ $30, \mathrm{SZ} 30 / 20, \mathrm{SZ} 35$, and SZ 40 groups, respectively).

At cesarean on day 20, no differences were detected in litter size, total live litter weight, and number of resorptions among the groups (data not shown). Groups that were hyperglycemic throughout pregnancy (SZ 30/30 and SZ 50) had smaller fetuses and larger placentas (Table 1); these fetuses were severely hyperglycemic, but no difference in insulin concentration was detected. Animals with hyperglycemia on day 6 (SZ

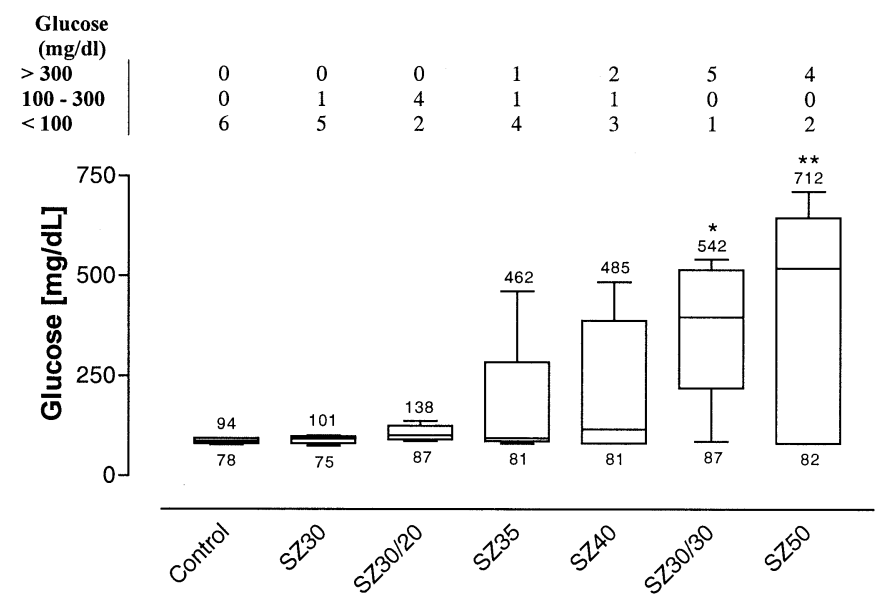

Figure 2. Box-and-whisker plots of plasma nonfasting glucose levels on day 20 of pregnancy in control and SZ-injected rats. Each group contained six rats. The lowest and highest values are shown for each group. Above the graph, we also show the number of rats in each group that had post-SZ glucose levels below $100 \mathrm{mg} / \mathrm{dL}$ (normal), 100-300 mg/dL (moderate hyperglycemia), and over $300 \mathrm{mg} / \mathrm{dL}$ (severe hyperglycemia). One-way ANOVA indicated a highly significant difference among the groups $(P<.001)$, and the post hoc test (Fisher's LSD) revealed significant differences versus controls $\left({ }^{*} P<\right.$ .005 and $* * P<.001)$.

40) also had smaller fetuses and larger placentas, but fetal glucose levels were not significantly elevated. Among the nonhyperglycemic groups (SZ 30, 30/20, and 35), fetal weight was lower only in the SZ 35 group, and there was no effect on placental weight or fetal glucose levels. Fetal insulin concentrations were higher in SZ 30, 30/20, and 35 compared with controls.

\section{IVGTT and Fetal Data in the SZ 35 and SZ $30 / 20$ Groups (Study 2)}

No differences were detected in fasting glucose levels of the SZ 35 and SZ 30/20 groups compared with controls (Figure 3). Glucose levels tended to be higher at 10 minutes (ANOVA $P$ $=.06$ ) and 15 minutes (ANOVA $P=.09$ ) after the glucose load in the SZ 35 and SZ 30/20 groups. At the 30-minute time point (ANOVA $P=.036$ ), glucose levels were significantly higher in both groups than in controls, whereas at the 60minute time point (ANOVA $P=.045$ ), glucose levels were higher in the SZ 35 group only. The AUC was significantly elevated in the SZ 35 but not the SZ 30/20 group compared with controls. No significant differences were detected in insulin concentrations, either fasting or at any time point during the IVGTT, and in the AUC.

Cesarean delivery on day 22 showed that fetuses in both SZ 35 and 30/20 groups were smaller than those of controls (Table 1). Placental weight, fetal plasma glucose, and insulin concentrations was not significantly different among the groups (ANOVA $P=.054, P=.058$, and $P=.76$, respectively). Glucose concentrations were higher on day 22 than on day 20 in fetuses of control and SZ 30/20 rats, but not in fetuses of SZ 35 rats $(P=.19)$. Fetal insulin concentrations 
Table 1. Fetal and Placental Weight, and Fetal Plasma Glucose and Insulin Concentrations on Days 20 and 22 of Intrauterine Life

\begin{tabular}{|c|c|c|c|c|c|c|c|c|}
\hline \multirow[b]{2}{*}{ Group } & \multicolumn{2}{|c|}{ Fetal weight (g) } & \multicolumn{2}{|c|}{ Placental weight (g) } & \multicolumn{2}{|c|}{ Fetal glucose $(\mathrm{mg} / \mathrm{dL})$} & \multicolumn{2}{|c|}{ Fetal insulin $(\mathrm{mU} / \mathrm{L})$} \\
\hline & Day 20 & Day 22 & Day 20 & Day 22 & Day 20 & Day 22 & Day 20 & Day 22 \\
\hline Control & $2.21 \pm 0.02(75)$ & $5.15 \pm 0.04^{\mathrm{aa}}(72)$ & $0.52 \pm 0.01(75)$ & $0.60 \pm 0.01^{\mathrm{aa}}(73)$ & $45 \pm 4(12)$ & $106 \pm 7^{\text {aa }}(12)$ & $98 \pm 7(12)$ & $235 \pm 17^{\text {aa }}(12)$ \\
\hline SZ 30 & $2.17 \pm 0.02(74)$ & & $0.51 \pm 0.01(74)$ & & $46 \pm 3(12)$ & & $149 \pm 16^{*}(12)$ & \\
\hline SZ $30 / 20$ & $2.26 \pm 0.02(78)$ & $4.83 \pm 0.04^{\text {*aа }}(83)$ & $0.53 \pm 0.01(78)$ & $0.56 \pm 0.01^{\text {aa }}(74)$ & $52 \pm 5(12)$ & $114 \pm 5^{\text {aa }}(12)$ & $156 \pm 19^{\dagger}(12)$ & $265 \pm 47^{\text {aa }}(12)$ \\
\hline SZ 35 & $2.11 \pm 0.02 *(70)$ & $4.64 \pm 0.05^{\text {‡aa }}(69)$ & $0.50 \pm 0.01(72)$ & $0.59 \pm 0.01^{\text {aа }}(71)$ & $111 \pm 34(12)$ & $184 \pm 45(12)$ & $151 \pm 12 *(12)$ & $259 \pm 19^{\text {aa }}(12)$ \\
\hline SZ 40 & $2.11 \pm 0.02^{\ddagger}(73)$ & & $0.61 \pm 0.01^{\ddagger}(73)$ & & $134 \pm 41(12)$ & & $101 \pm 13(12)$ & \\
\hline SZ $30 / 30$ & $1.93 \pm 0.02^{\ddagger}(89)$ & & $0.61 \pm 0.01^{\ddagger}(89)$ & & $308 \pm 42^{\ddagger}(12)$ & & $65 \pm 11(12)$ & \\
\hline SZ 50 & $1.95 \pm 0.03^{\ddagger}(67)$ & & $0.61 \pm 0.02^{\ddagger}(67)$ & & $410 \pm 61^{\ddagger}(11)$ & & $113 \pm 20(11)$ & \\
\hline
\end{tabular}

Data are mean \pm standard deviation of the mean from six rats per group. The number of fetal measurements is given in parentheses (fetal blood was pooled per uterine horn). For most variables (all variables on day 20 and fetal weight on was not significant for placental weight $(P=.054)$, fetal glucose $(P=.06)$, and insulin $(P=.76)$ on day 22 . In the control, SZ 30/20, and SZ 35 groups, the data from day 22 were compared with those of day 20 by unpaired $t$ tests (aa $P$ $<$.001).
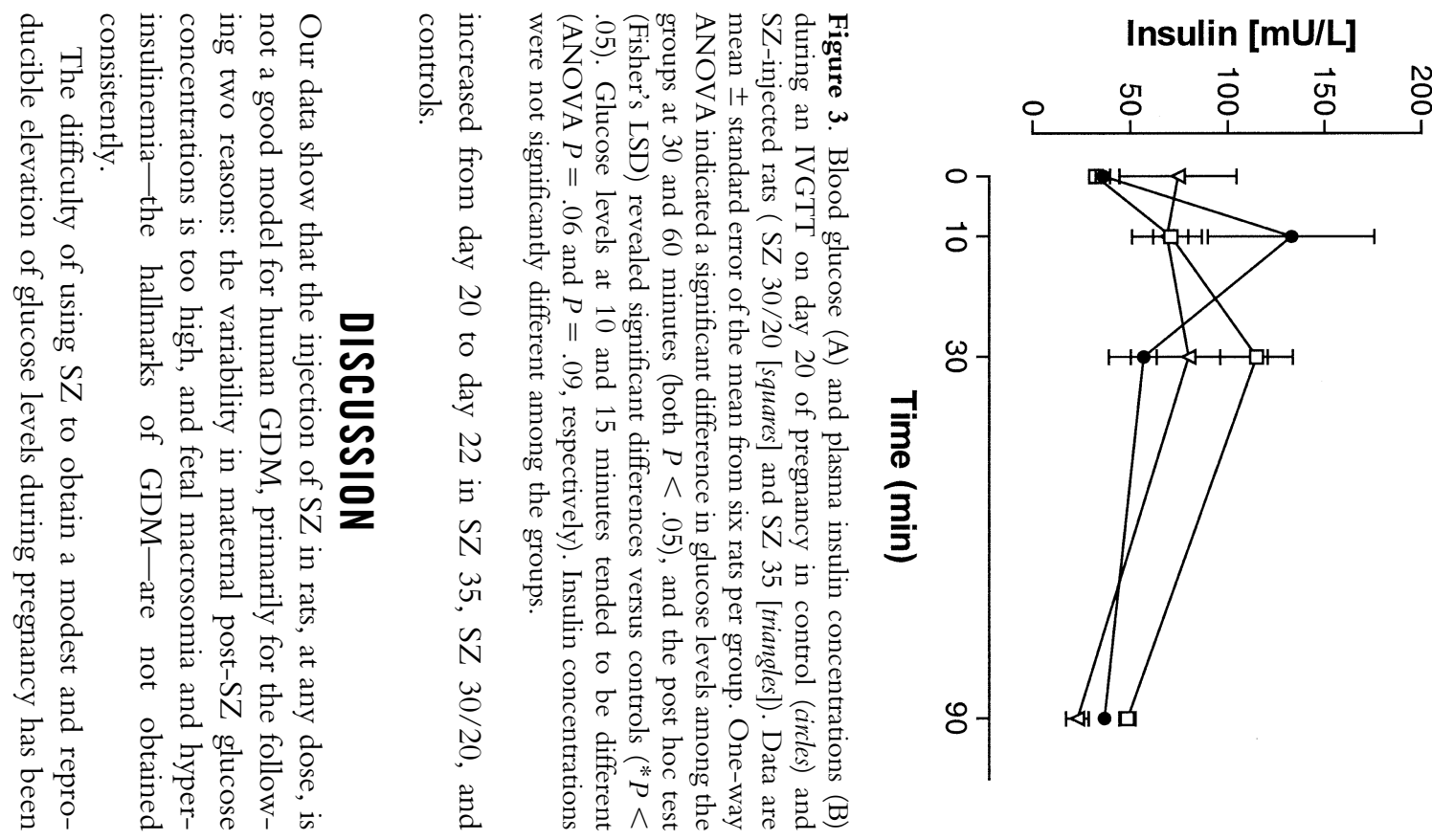

ш

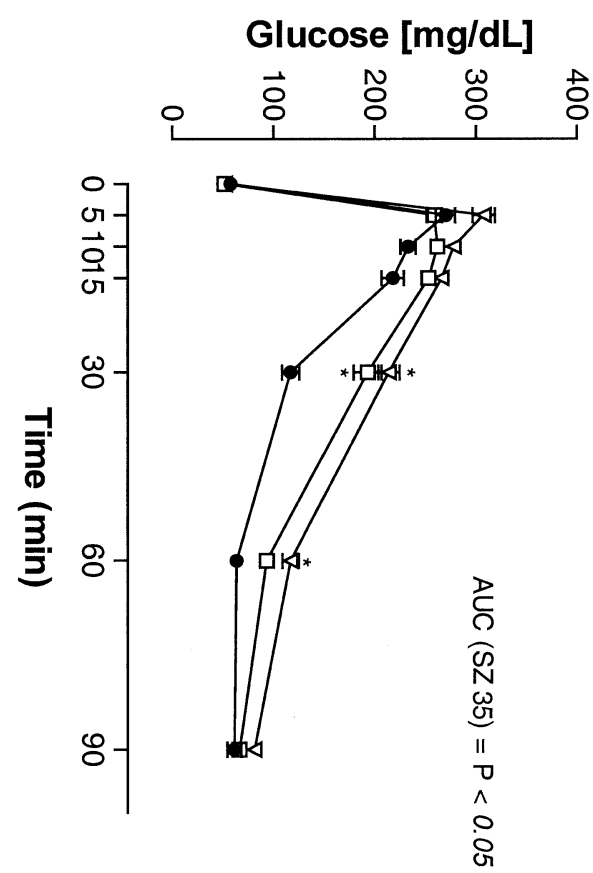


acknowledged previously. Some groups have therefore used predefined post-SZ glucose levels. Oh et $\mathrm{al}^{24}$ obtained modest hyperglycemia (ie, glucose between 100 and $300 \mathrm{mg} / \mathrm{dL}$ ) in $48 \%$ using SZ 35, and Merzouk et $\mathrm{al}^{25}$ succeeded in $60 \%$ of rats using SZ 40. In this study, SZ 30/20 appeared to be the best mode of administration to achieve this goal, but in the IVGTT experiment, glucose intolerance was not readily apparent. A significant deterioration in glucose tolerance was observed with SZ 35, but only one of six animals had modest hyperglycemia in this group. Although the data were obtained in separate experiments, it is nonetheless clear that modest nonfasting hyperglycemia does not adequately reflect the blood glucose response to a glucose load in fasting rats. Neither SZ 30/20 nor SZ 35 produced any change in insulin concentrations during the IVGTT. This finding contrasts with data in human GDM, which is characterized by a deficient early insulin response during an IVGTT. ${ }^{4} \mathrm{SZ} 30 / 30$ and 50 were most likely to result in severe hyperglycemia $(>300 \mathrm{mg} / \mathrm{dL})$, although there was considerable variability within these SZ doses as well. Because SZ 30/30 did not result in extreme hyperglycemia $(>600 \mathrm{mg} / \mathrm{dL}$ ) in any of the animals, it may be preferred to SZ 50 to produce severe diabetes. Both high-dose SZ groups were predictably accompanied by relative hypoinsulinemia.

We found that fetal insulin concentrations on day 20 were elevated in the SZ 30, 30/20, and 35 groups, which suggests that fetal glucose levels were sufficiently elevated to stimulate insulin secretion. This finding confirms reports of elevated fetal insulin concentrations in rats treated with low doses of SZ. ${ }^{22-25}$ However, on day 22 (ie, at term), fetal insulin concentrations in the SZ 30/20 and 35 groups were not significantly different from controls, although the fetal blood samples had been obtained by identical methods. Fetal insulin concentrations increased between day 20 and 22 by $70-140 \%$, which confirms the findings of previous studies. ${ }^{26,27}$ Higher doses of SZ (SZ $30 / 30$ and 50) were accompanied by unequivocal fetal hyperglycemia but did not affect fetal insulin concentrations. In several of our previous studies, ${ }^{16,22,28}$ we found fetal insulin levels to be lower in severely diabetic rats, and we produced histologic and ultrastructural evidence that this is the result of degranulation of the fetal $\beta$ cells. ${ }^{16,22}$

Some researchers have reported fetal macrosomia in rats injected with low doses of SZ, but, again, they used predefined selection methods. Kim et $\mathrm{al}^{23}$ injected rats with SZ 32, and they were subsequently mated if glucose levels were between 130 and $200 \mathrm{mg} / \mathrm{dL}$. Macrosomia, defined as the mean fetal weight of controls +2.5 standard deviations, was observed in $14 \%$ of fetuses on day 20.5. Other investigators used comparable criteria to define macrosomia (eg, the mean birth weight of control pups +1.7 standard deviations). ${ }^{24,25}$ In the lowerdose groups (SZ 30, 30/20, and 35), we found that the average fetal weight was lower in SZ 35 rats on days 20 and 22, and in SZ 30/20 rats on day 22; SZ 30 rats had a normal fetal weight, but they were examined only on day 20. Applying the above criteria for macrosomia (fetal weight of controls +1.7 standard deviations), $4.1 \%$ (three of 74 ), $5.1 \%$ (four of 78 ), and $0 \%$ of the fetuses were macrosomic on day 20 in the SZ 30, 30/20, and 35 groups, respectively, which is statistically at or below the expected percentage. Our findings are in line with previous data ${ }^{19,20}$ showing that fetal macrosomia is not a feature of SZ-diabetic pregnant rats. This finding is not surprising because rat fetuses are chemically immature. At birth, only $2 \%$ of body weight is fat tissue in rats, compared with $16 \%$ in humans. ${ }^{29,30}$

In conclusion, the injection of lower doses of $\mathrm{SZ}$ in rats is not an adequate model for human GDM because of the high variability in nonfasting glucose levels, the absence of a deficient early insulin response to glucose load, the lack of consistent fetal hyperinsulinemia, and the absence of fetal macrosomia. Other models for GDM need to be explored. Fu et $\mathrm{al}^{31}$ injected pregnant rats with SZ 55 and transplanted pancreatic islets from donor rats, thus obtaining rats with mild glucose intolerance; newborn body weight was elevated by $14 \%$. Another interesting model of GDM was recently described in mice. ${ }^{32,33}$ Mice heterozygous for the leptin receptor $\left(\mathrm{Lepr}^{\mathrm{db} /+}\right)$ had increased weight gain during pregnancy and showed glucose intolerance with higher insulin concentrations. The weight of heterozygous fetuses was increased by $7 \%$ on day 18 of pregnancy, and fetal insulin levels were higher compared with wild-type fetuses. The relation between obesity, insulin resistance, and glucose intolerance during pregnancy in animal models is a promising avenue for future research on GDM.

\section{REFERENCES}

1. Engelgau MM, Herman WH, Smith PJ, German RR, Aubert RE. The epidemiology of diabetes and pregnancy in the U.S., 1988. Diabetes Care 1995;18:1029-33.

2. Feig DS, Palda VA. Type 2 diabetes in pregnancy: A growing concern. Lancet 2002;359:1690-2.

3. Solomon CG, Willett WC, Carey VJ, et al. A prospective study of pregravid determinants of gestational diabetes mellitus. JAMA 1997;278:1078-83

4. Xiang AH, Peters RK, Trigo E, Kjos SL, Lee WP, Buchanan TA. Multiple metabolic defects during late pregnancy in women at high risk for type 2 diabetes. Diabetes 1999;48:848-54.

5. Jacobson JD, Cousins L. A population-based study of maternal and perinatal outcome in patients with gestational diabetes. Am J Obstet Gynecol 1989;161:981-6.

6. Hellerström C, Swenne I, Eriksson UJ. Is there an animal model for gestational diabetes? Diabetes 1985;34(Suppl 2):28-31.

7. Elsner M, Guldbakke B, Tiedge M, Munday R, Lenzen S. Relative importance of transport and alkylation for pancreatic beta-cell toxicity of streptozotocin. Diabetologia 2000;43:152833.

8. Aughsteen AA. An ultrastructural study on the effect of streptozotocin on the islets of Langerhans in mice. J Electron Microsc (Tokyo) 2000;49:681-90.

9. Okamoto H. Molecular basis of experimental diabetes: Degeneration, oncogenesis and regeneration of pancreatic B-cells of islets of Langerhans. Bioessays 1995;2:15-21.

10. Schein PS, Loftus S. Streptozotocin: Depression of mouse liver pyridine nucleotides. Cancer Res 1968;28:1501-6.

11. Yang $H$, Wright JR. Human $\beta$ cells are exceedingly resistant to streptozotocin in vivo. Endocrinology 2002;143:2491-5.

12. Sybulski S, Maughan GB. Use of streptozotocin as diabetic agent in pregnant rats. Endocrinology 1971;89:1537-40. 
13. Bell RH, Hye RJ. Animal models of diabetes mellitus: Physiology and pathology. J Surg Res 35 1983;35:433-60.

14. Aerts L, Holemans K, Van Assche FA. Maternal diabetes during pregnancy: Consequences for the offspring. Diabetes/Metabolism Rev 1990;6:147-67.

15. Holemans K, Van Bree R, Verhaeghe J, Aerts L, Van Assche FA. In vivo glucose utilization by individual tissues in virgin and pregnant offspring of severely diabetic rats. Diabetes 1993;42: 530-6.

16. Verhaeghe J, Peeters TL, Vandeputte M, Rombauts W, Bouillon $\mathrm{R}$, Van Assche FA. Maternal and fetal endocrine pancreas in the spontaneously diabetic BB rat. Biol Neonat 1989;55:298-308.

17. Eriksson UJ, Jansson L. Diabetes in pregnancy: Decreased placental blood flow and disturbed fetal development in the rat. Pediatr Res 1984;18:735-8.

18. Mulay S, Philip A, Solomon S. Influence of maternal diabetes on fetal rat development: Alteration of insulin receptors in fetal liver and lung. J Endocrinol 1983;98:401-10.

19. Eriksson U, Andersson A, Efendic S, Elde R, Hellerström C. Diabetes in pregnancy: Effects on the foetal and newborn rat with particular regard to body weight, serum insulin concentration and pancreatic contents of insulin, glucagons and somatostatin. Acta Endocrinol 1980;94:354-64.

20. Herrera E, Palacin M, Martin A, Lasuncion MA. Relationship between maternal and fetal fuels and placental glucose transfer in rats with maternal diabetes of varying severity. Diabetes 1985; 34(Suppl 2):42-6.

21. Golob EK, Rishi S, Becker KL, Moore C, Shah N. Effect of streptozotocin-induced diabetes on pancreatic insulin content of the fetus. Diabetes 1970;19:610-3.

22. Aerts L, Van Assche FA. Rat foetal endocrine pancreas in experimental diabetes. J Endocrinol 1977;73:339-46.
23. Kim YS, Yoon Y, Jatoi I, Kim Y. Fetal macrosomia in diabetic multiparous animals. Diabetologia 1981;20:213-6.

24. Oh W, Gelardi NL, Cha CJ. Maternal hyperglycemia in pregnant rats: Its effect on growth and carbohydrate metabolism in the offspring. Metabolism 1988;37:1146-51.

25. Merzouk H, Madani S, Chabane Sari D, Prost J, Bouchenak M, Belleville J. Time course of changes in serum glucose, insulin, lipids and tissue lipase activities in macrosomic offspring of rats with streptozotocin-induced diabetes. Clin Sci 2000;98:21-30.

26. Girard JR. Metabolic fuels of the fetus. Isr J Med Sci 1975;11: 591-600.

27. Goodner CJ, Thompson DJ. Glucose metabolism in the fetus in utero: The effect of maternal fasting and glucose loading in the rat. Pediatr Res 1967;1:443-51.

28. Holemans K, Van Bree R, Verhaeghe J, Meurrens K, Van Assche FA. Maternal semistarvation and streptozotocin-diabetes in rats have different effects on the in vivo glucose uptake by peripheral tissue in their female adult offspring. J Nutr 1997;127:1371-6.

29. Widdowson EM. Chemical composition of newly born mammals. Nature 1950;166:1626-8.

30. Stangenberg M, Eklöf A, Dahlquist G, Persson B. Lack of effect on body weight and content of nitrogen and fat after insulin administration to fetal rats. Biol Neonate 1981;40:240-5.

31. Fu Q, Honda M, Ohgawara H, et al. Morphological analysis of pancreatic endocrine cells in newborn animals delivered by experimental diabetic rats. Diabetes Res Clin Pract 1996;31:57-62.

32. Ishizuka T, Klepcyk P, Liu S, Panko L, Gibbs EM, Friedman JE. Effects of overexpression of human GLUT 4 gene on maternal diabetes and fetal growth in spontaneous gestational diabetic C57BLKS/J Lepr ${ }^{\mathrm{db} /+}$ mice. Diabetes 1999;48:1061-9.

33. Lawrence S, Warshaw J, Nielsen HC. Delayed lung maturation in the macrosomic offspring of genetically determined diabetic $\mathrm{db} /+$ mice. Pediatr Res 1989;25:173-9. 